\title{
Canaliculite: relato de caso e conduta
}

\author{
Canaliculitis: case report and management
}

\author{
Rachel Camargo Carneiro ${ }^{1}$ \\ Erick Marcet Santiago de Macedo ${ }^{2}$ \\ Patrícia Paula Deboni Greenhalgh de Oliveira ${ }^{3}$
}

\section{RESUMO}

A canaliculite é uma infecção rara do canalículo lacrimal, sendo o Actinomyces israelii o agente causal mais comum. O objetivo desse trabalho foi relatar uma doença rara, assim como seu manejo clínico e cirúrgico. Paciente feminina, 44 anos, apresentou um quadro compatível com canaliculite, sendo submetida à canaliculotomia com preservação do ponto lacrimal. A via lacrimal foi mantida intubada com tubo de silicone por 3 meses, associado a irrigações periódicas, com antibiótico, a fim de evitar complicações e a recidiva do quadro. $\mathrm{O}$ caso apresentado confirma os relatos da literatura nos quais o tratamento cirúrgico mostrouse superior ao conservador.

Descritores: Actinomyces/isolamento \& purificação; Infecções oculares bacterianas/ cirurgia; Curetagem/métodos; Doenças do aparelho lacrimal/cirurgia; Adulto; Feminino; Relatos de casos [Tipo de publicação]

\section{INTRODUÇÃO}

As infecções primárias dos canalículos são incomuns. O agente causal mais comum é o Actinomyces israellii ${ }^{(1-7)}$; bactéria gram positiva, anaeróbica, de difícil isolamento e identificação. Existem outros agentes menos freqüentes como o caso de infecções virais por herpes simples em pacientes abaixo dos 20 anos, infecções por Fusarium, Cândida, Propinebacterium, Enterobacter, Nocardias e espécies de Aspergillus. Com menos freqüência pode resultar de uma complicação por uso de plugs de silicone e após tratamento por quimioterapia utilizando o 5-fluoracil ${ }^{(8-11)}$.

As manifestações clínicas mais freqüentes são epífora, irritação ocular e desconforto no canto medial, acompanhado por sinais de secreção ocular, eritema e espessamento da pálpebra medial, edema e refluxo de secreção no ponto lacrimal. Eventualmente pode ocorrer a exteriorização de concreções (dacriolitos) pelo ponto ${ }^{(8,12)}$. Sempre devemos considerar como diagnóstico diferencial de canaliculite os casos de conjuntivite intermitente, principalmente quando a apresentação for unilateral, crônica e não responsiva ao tratamento convencional ${ }^{(13-14)}$.

O envolvimento de vias lacrimais baixa não é comum poupando o saco lacrimal e ducto lacrimo-nasal. Na maioria dos casos a via lacrimal se mantém pérvia.

A canaliculite apesar de ser uma infecção rara, não sofre melhora espontânea, portanto o tratamento proposto em nosso serviço foi a canaliculotomia com preservação do ponto lacrimal ${ }^{(8,15-16)}$ e intubação da via lacrimal com tubo de silicone.

\section{OBJETIVO}

Reportar o quadro clínico de uma doença rara, assim como seu manejo clínico e cirúrgico. 


\section{RELATO DE CASO}

A.F.A; feminina; 44 anos; branca; casada; natural do Rio de Janeiro; doméstica.

Foi encaminhada ao setor de Oculoplástica e vias lacrimais do HSE - RJ, referindo há um ano quadro de secreção purulenta e hiperemia em olho esquerdo. Fez tratamento com antibiótico tópico e compressas mornas sem resolução do quadro.

Ao exame clínico inicial apresentava dilatação, hiperemia e edema do ponto lacrimal inferior com saída de secreção purulenta, por este, à expressão (Figura 1).

Foi realizada a exploração clínica das vias lacrimais, onde foram observadas concreções à sondagem com irrigação pérvia.

Mediante o quadro supracitado optamos por intervenção cirúrgica, portanto solicitamos exames pré-operatórios e suspensão da antibioticoterapia utilizada anteriormente.

A cirurgia realizada foi canaliculotomia preservando o ponto lacrimal onde se observou, após curetagem exaustiva, saída de grande quantidade de secreção e dacriolitos. (Figuras 2 e 3 ).

Foi feito irrigação local com solução de penicilina $G$ cristalina $^{(2,8,11,16)} 1: 160.000 \mathrm{U} / \mathrm{ml}$ imediatamente após o procedimento cirúrgico, além disso, optamos por manter via lacrimal intubada com tubo de silicone (Figura 4).

O material colhido foi enviado ao laboratório para realização de gram e cultura com resultado positivo para Actinomyces $\mathrm{sp}$.

No acompanhamento ambulatorial foi prescrito ofloxacino $0,3 \%$ colírio 4 vezes ao dia por 15 dias e irrigações periódicas com ofloxacino conforme o esquema abaixo:

- Primeiro mês - $1 \mathrm{vez} / \mathrm{semana}$

- Segundo mês - 1 vez/15 dias

- Terceiro mês - Retirada do silicone da via lacrimal e irrigação imediata.

A paciente permanece assintomática após 6 meses.

\section{DISCUSSÃO}

A canaliculite é uma infecção rara do canalículo lacrimal, que na maioria das vezes não é adequadamente tratada devido à confusão em seu diagnóstico ${ }^{(1,7,17)}$.

Inúmeras técnicas foram propostas para o seu tratamento e a conduta cirúrgica mostrou-se superior ao tratamento conservador $^{(7,8,15-16)}$. Alguns autores relataram em sua casuística apenas uma taxa de $20 \%$ de cura completa quando o tratamento conservador foi utilizado isoladamente ${ }^{(15)}$.

O tratamento cirúrgico consiste na realização de uma canaliculotomia que pode envolver ou não o ponto lacrimal. Em uma das técnicas é realizada uma incisão horizontal posterior do canalículo com 5 a $8 \mathrm{~mm}$ de extensão, iniciando a $2 \mathrm{~mm}$ medialmente ao ponto lacrimal. Após a curetagem com cureta de calázio de 1 a 2 mm, realiza-se a entubação bicanalicular com

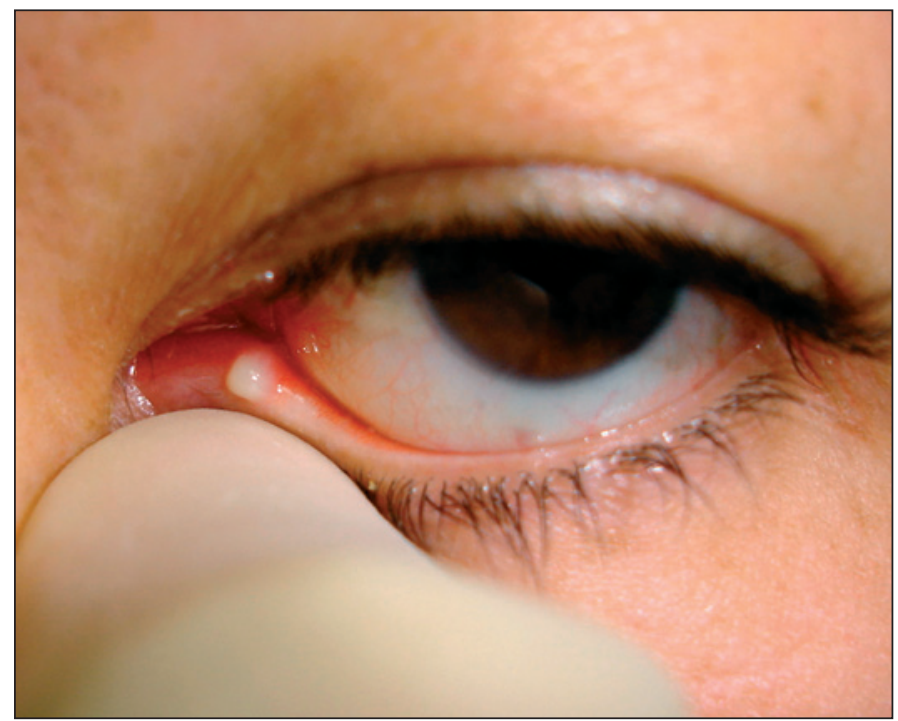

Figura 1 - Secreção purulenta e hiperemia no olho esquerdo

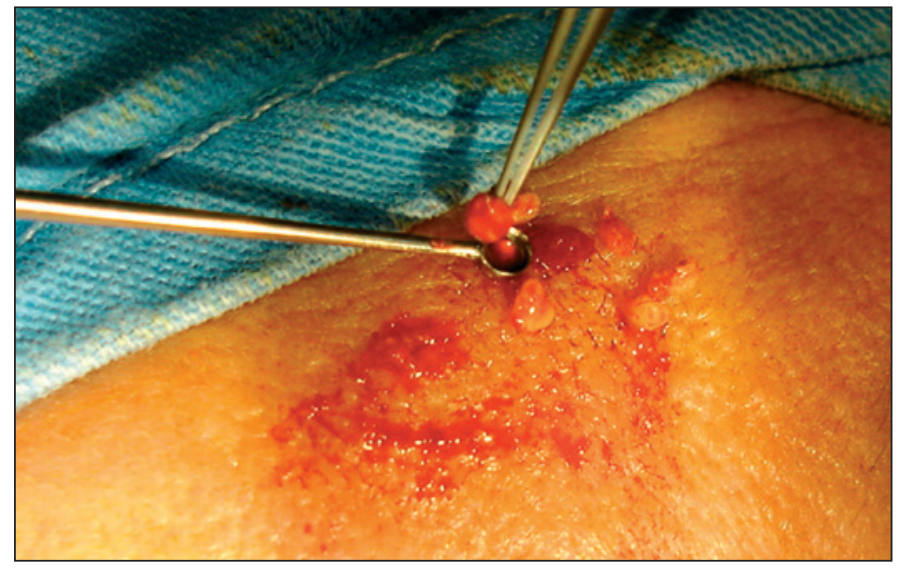

Figura 2 - Concreções após curetagem exaustiva

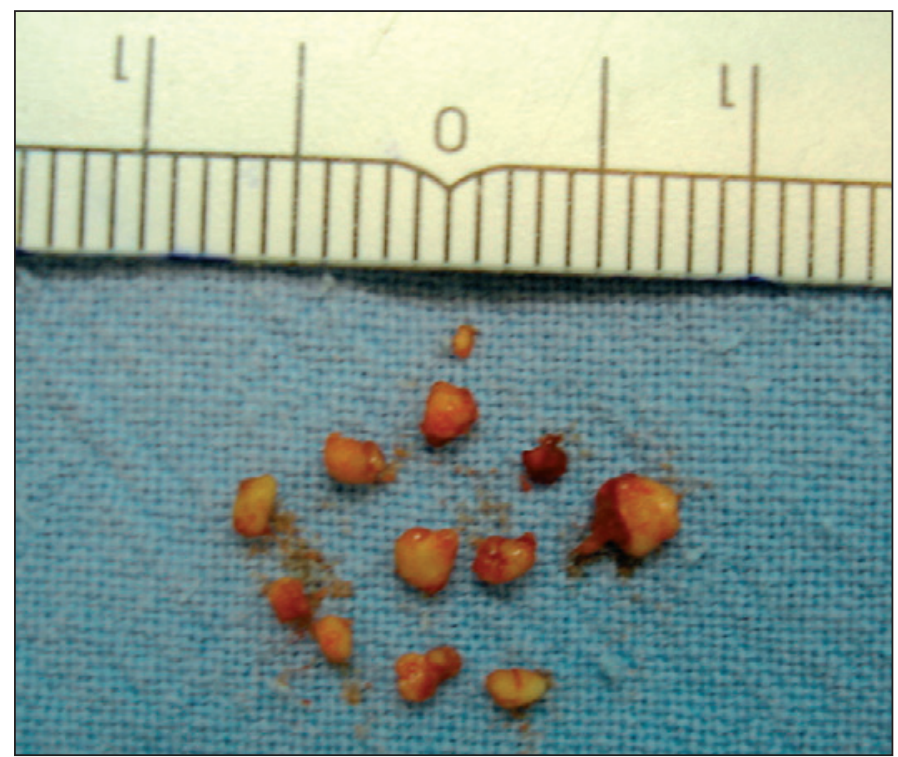

Figura 3 - Material colhido 


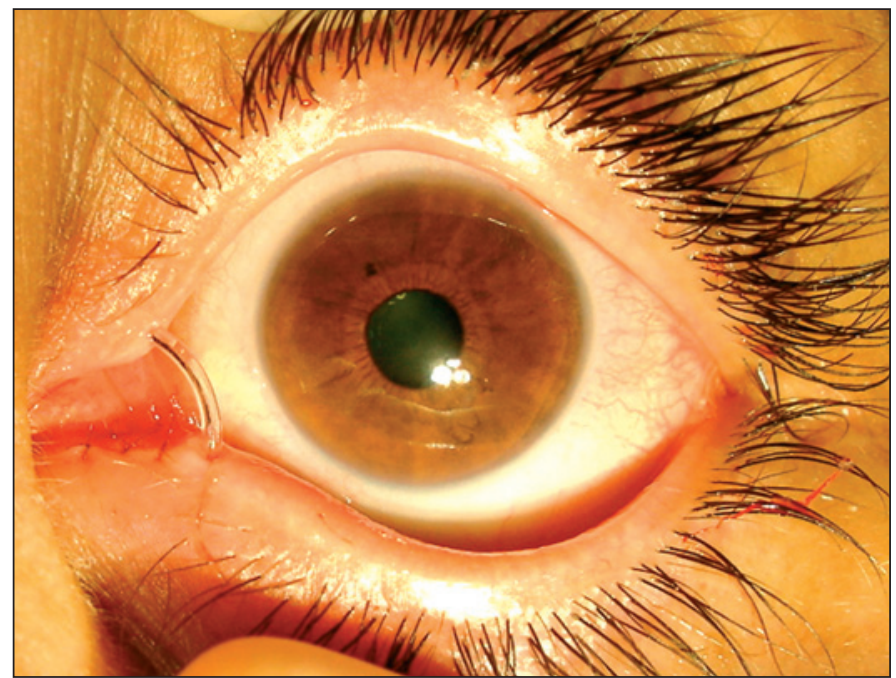

Figura 4 - Via lacrimal intubada com tubo de silicone

tubo de silicone e sutura do canalículo com fio 8.0 ou 9.0 não absorvível.

O tubo de silicone permanecerá por 3 meses associado à irrigações periódicas com antibiótico tópico. Na outra técnica a incisão é realizada a partir do ponto lacrimal, o canalículo não é suturado e a intubação com tubo de silicone não é realizada.

Além disso, tem sido observado como complicações da canaliculotomia que inclui o ponto lacrimal, a epífora assim como a recidiva do quadro. Visando evitar essas complicações, realizou-se a canaliculotomia com preservação do ponto lacrimal, intubação da via lacrimal por 3 meses e irrigações periódicas.

\section{ABSTRACT}

Canaliculitis is a rare infection of the lacrimal canaliculus with Actinomyces israelii as its most common etiologic agent. The objective of this paper is to report a rare pathology, as well as its clinical and surgical management. Female patient, 44 years old, presenting clinical manifestations compatible with canaliculitis, was submitted to surgical treatment preserving the lacrimal punctum. Intubation was performed into the lacri- mal channel with silicone tube for three months, associated with periodical pre-programmed bathings with antibiotic, in order to avoid complications and recurrence. This case confirms the literature reports in which the surgical treatment is more effective than the conservative treatment.

Keywords: Actinomyces/isolation \& purification; Eye infections, bacterial/surgery; Curettage/methods; Lacrimal apparatus diseases/surgery; Adult; Female; Case reports [Publication type]

\section{REFERÊNCIAS}

1. Hass C, Pittasch K, Handrick W, Tauchnitz R. [Actinomycetes canaliculitis - case reports]. Immum Infekt. 1995;23(6):222-3. German.

2. Struck HG, Hohne C, Tost M. [Diagnosis and therapy of chronic canaliculitis]. Ophthalmologe. 1992;89(3):223-6. German.

3. Hirst LW, Merz WB, Kaufmann CS. Actinomyces/Arachnia lacrimal canaliculitis. Cornea. 1982;1:259.

4. Smith RL, Henderson PN. Actinomycotic canaliculitis. Aust J Ophthalmol 1980;8(1):75-9.

5. Jones DB, Robinson NM. Anaerobic ocular infections. Trans Sect Ophthalmol Am Acad Ophthalmol Otolaryngol. 1977;83(2):309-31.

6. Schaal KP, Schofield GM, Pulverer G. Taxonomy and clinical significance of Actinomycetaceae and Propionibacteriaceae. Infection. 1980;8(Suppl 2):S122-30.

7. Benchimol ML, Couto Jr. AS, Pereira CF, Melo AC, Barbosa RS. Canaliculite: Relato de casos e conduta. Arq Bras Oftalmol. 2002;65(4):471-3.

8. McKellar MJ, Aburn NS. Cast-forming Actinomyces israelii canaliculitis Aust N Z J Ophthalmol. 1997;25(4):301-3.

9. García-Layana A, Munuera JM, Moreno J, Sainz A. Canaliculitis por actinomyces: diagnóstico y tratamiento quirúrgico. Arch Soc Esp Oftalmol. 1997; 72:291-4.

10. Melero P, Alvarez M, Llanos A, Pérez JM, Salaverri F, Cistema R. Canaliculitis por Actinomyces israelii. Enferm Infecc Microbiol Clin. 1994;12:109-10.

11. Herrera Soto M, Gómez Cabrera C, Agramonte Centelles I. Canaliculitis: diagnóstico clínico y resultados quirúrgicos. Rev Cuba Oftalmol. 2004;17(1):1-2.

12. Carvalho RM, Fernandes JB, Volpini M, Matayoshi S, Moura EM. Tratamento cirúrgico das canaliculites crônicas: relato nossa experiência em 7 casos. Arq Bras Oftalmol. 2001;64(6):519-21.

13. Alves MR, Kara Jose N. Conjuntivite crônica. In: Alves MR, Kara Jose N, editores. Conjuntiva cirúrgica - atualidades em Oftalmologia. São Paulo: Rocca; c1999. vol. 1, p.1-5.

14. Demant E, Hurwitz JJ. CanaliculitIs: review of 12 cases. Can J Ophthalmol. 1980;15(2):73-5.

15. Vécsei VP, Huber-Spitzy V, Arocker-Mettinger C, Steinkogler FJ. Canaliculitis: difficulties in diagnosis, differential diagnosis and comparison between conservative and surgical treatment. Ophthalmologica. 1994;208(6):314-7.

16. Pavilack MA, Frueh BR. Through curettage in the treatment of chronic canaliculitis. Arch Ophthalmol. 1992;110(2):200-2.

17. Richards WW. Actinomycotic lacrimal canaliculitis. Am J Ophthalmol. 1973; 75(1):155-7.

Ao enviar um artigo para publicação, leia ATENTAMENTE as instruções para autores, constante no final de cada fascículo. 